\title{
Telehealth Approaches to Care Coordination in Autism Spectrum Disorder
}

\author{
Dasha Solomon and Neelkamal Soares
}

\begin{abstract}
This chapter examines the current literature regarding the use of telehealth, and its potential benefits and limitations for diagnosis, treatment, and coordination of care for children diagnosed with Autism Spectrum Disorder (ASD). Barriers to access drive the need to have telehealth as a modality for delivering evidencebased diagnostic and therapeutic processes, which can be impactful in improving developmental trajectories and functional outcomes. The chapter concludes with guidance for clinicians interested in leveraging telehealth, with directions elucidated to further advance the use of telehealth to support families with ASD. More recently, in light of Coronavirus disease 2019 (COVID-19) pandemic and social distancing guidelines and restrictions, this chapter highlights changes in telehealth policy and the use of telehealth for diagnosis and treatment of ASD as well as thoughts about future directions.
\end{abstract}

This chapter examines current literature regarding the use of telehealth, potential benefits and limitations for diagnosis, treatment, and coordination of care for Autism Spectrum Disorder (ASD). Telehealth may help to bridge the "detection gap" seen between urban and rural communities and expedite access to care during the crucial toddler years, when evidence-based treatments can be especially impactful in improving developmental trajectories and functional outcomes (Wagner et al., 2015; Warren et al., 2011). Children, adolescents, and adults with ASD present with many unique challenges but also have a number of strengths that may make them an especially good target audience for teletherapy interventions.

D. Solomon

Boston Children's Hospital, Harvard Medical School, Boston, MA, USA

N. Soares $(\varangle)$

Pediatric and Adolescent Medicine, Western Michigan University Homer Stryker M.D. School of

Medicine, Kalamazoo, MI, USA

e-mail: neelkamal.soares@med.wmich.edu 


\section{Access and ASD Services}

Current prevalence of ASD is reported as 1 in 54 children in the United States (US) (Maenner, Shaw, Baio, et al., 2020), affecting individuals across all racial, ethnic, and socioeconomic groups equally. Early diagnosis can help parents connect with providers and resources in their community, as well as obtain genetic counseling (Shattuck et al., 2009). However, although parents often notice differences in their child's development between 15 and 22 months, ASD is typically diagnosed when a child is 3 years or older (Johnson \& Myers, 2007; Zuckerman, Lindly, \& Sinche, 2015), and in more rural communities, the average age of diagnosis is around age 7 (Shattuck et al., 2009). One possible reason is the paucity of qualified professionals: a recent survey of medical professionals who work with developmental disabilities across the US concluded that there are challenges in meeting the current service demands (initial diagnosis and ongoing care), resulting in long wait times for appointments (Bridgemohan et al., 2018). Others have also highlighted that overburdened providers, combined with a growing demand, often lead to wait times that can exceed 12 months for an initial diagnostic appointment and can be even longer in rural communities (Chiri \& Warfield, 2012; Dawson \& Bernier, 2013; Gordon-Lipkin, Foster, \& Peacock, 2016; Siklos \& Kerns, 2007). Ning et al. found that $84 \%$ of US counties did not have ASD diagnostic resources (Ning et al., 2019).

Delays in definitive diagnosis have significant downstream effects: in many areas, families who are waiting to be evaluated can typically only access more general services from early intervention providers or special education and thus may miss out on ASD-specific therapy, (Pierce et al., 2011; Stahmer \& Mandell, 2007). These challenges are magnified for families from traditionally underserved populations such as those with lower income, racial minorities, families with less formal education, and for those who live in rural areas (Chlebowski, Robins, Barton, \& Fein, 2013; Zwaigenbaum et al., 2015). Thus, there is a need for the implementation of telehealth as a possible solution (among others) to reaching a wider range of families to provide initial diagnosis as well as therapeutic interventions (Gordon-Lipkin et al., 2016).

\section{Telehealth}

Telehealth is defined broadly as the "use of electronic information and telecommunications technologies to support long-distance clinical health care, patient and professional health-related education, public health and health administration"(Office for the Advancement of Telehealth, n.d.). For the purposes of this chapter, we will only discuss real-time audio-video ("synchronous") models, even though telehealth can broadly encompass "asynchronous" exchanges (images, videos, online patient portals) and mobile health (smart device applications or "apps" and wearable technology), which is beyond the scope of this chapter. Also, while we acknowledge that ASD is diagnosed and managed by a variety of disciplines (psychology, medicine, 
behavior analysis, speech-language therapy, education, among others), there is more literature in the medical domain than the others, which is reflected in this chapter. Also, some disciplines prefer the term telepractice rather than telehealth to convey the idea that these services aren't exclusively used in healthcare settings. To maintain consistency with the terminology, the term telehealth will be used moving forward.

\section{Technical Advances and Barriers}

There has been increased interest and uptake of telehealth in the last decade, in part due to increased awareness, and reduction in technological barriers. Broadband deployment has been expanded by the Federal Communications Commission (FCC) with about $98 \%$ of the US having access to either fixed or mobile connectivity, though it is less in rural areas (FCC, 2018). With 95\% of the US population owning a cell phone and 77\% owning a smartphone (Pew Research Center, n.d.), telehealth usage has increased from 2011 to 2016, 643\% overall (960\% in rural areas and 629\% in urban areas) (Fair Health Inc, 2018). Cost continues to be a barrier; softwarebased solutions can cost up to $\$ 3000$ and hard-based solutions can range from $\$ 7000$ to $\$ 30000$, not including training of staff. A larger hurdle is the integration of telehealth solutions with electronic health records (EHRs). Despite widespread adoption of the latter, only a few telehealth solutions are achieving integration, and not to a high degree of bidirectionality (KLAS, 2018). There are concerns by providers and professional societies about telehealth disrupting the provider-patient relationship if conducted in an on-demand fashion (Committee on Pediatric Workforce, 2015). Another barrier for provider adoption is lack of comfort with an unfamiliar technology (Utidjian \& Abramson, 2016), and fear of liability, though younger physicians are more willing to adopt telehealth compared to older physicians (American Well, 2019). Reimbursement for telehealth is often mentioned as the largest barrier to telehealth expansion (KLAS, 2017). It is not uniform, depending on the type of provider, the modality of telehealth being used, the insurance provider policy around telehealth, even the nature of the encounter (e.g., mental health versus medical). Not all states have "parity laws", i.e., equivalent reimbursement for telehealth as "in-person" care. Even states that require parity only require parity in covered services, not necessarily in reimbursement (Center for Connected Health Policy, 2019).

\section{Rationale for Telehealth with Children with ASD}

Telehealth has been used in clinical care for children and adolescents with developmental and behavioral concerns and disorders for several years. Telehealth is beginning to be viewed as an appropriate avenue of intervention given the limited supply of providers (and their general location in urban or suburban settings) and the nature 
of the encounter which relies on more observation and interviewing and less procedures (Soares \& Langkamp, 2012). In fact, for certain situations, telehealth might even be considered superior to in-person encounters. In ASD, this could be due to the novelty of the modality and that the separation (physical and psychological) allows for more naturalistic observations (Pakyurek, Yellowlees, \& Hilty, 2010). Since children and adolescents with ASD may not "travel well" to tertiary centers, the reduced burden of travel may also allow for more baseline/typical presentation and telehealth may also alleviate the geographic access barriers (Soares, Johnson, \& Patidar, 2013). The remainder of this chapter will review the literature regarding telehealth and diagnosis and treatment, as well as the feasibility and practical implementation of telehealth in ASD. Additionally, given the complex neurodevelopmental profile of many with ASD, telehealth allows multiple specialty providers to work with an individual which may provide a greater level of interprofessional care and collaboration among professionals.

\section{Telehealth and Diagnosis}

The process of diagnosing ASD is often multi-modal and complex, due to the lack of a definitive biological marker/test, the variability in ASD presentation and the need to consider DSM-5 criteria, functional abilities, and co-occurring or confounding conditions (Dawson \& Bernier, 2013; Filipek et al., 2000; Huerta \& Lord, 2012). As such, it often requires an in-depth developmental history (or diagnostic interview), observation of a child's social communication and behavior (usually through semi-structured diagnostic instruments), and an assessment of cognitive, adaptive, language, and behavioral functioning (Filipek et al., 2000). The utilization of multiple data modes and sources improves the reliability of ASD diagnosis (Huerta \& Lord, 2012). That said, the diagnostic process presents a challenge to telehealth as many of the validated psychological instruments used in ASD evaluations have not been translated into a telehealth format or rely on procedures that are hard to replicate at a distance. Many studies report the efficacy of telehealth evaluations use modified or adapted instruments and compare them against evaluation-as-usual instruments. For example, Reese and colleagues (Reese et al., 2013) administered a modified Autism Diagnostic Observation Schedule (ADOS) via video to children previously diagnosed with ASD or developmental delay to determine whether ASD symptoms could be observed using modified ADOS “presses". Results highlighted that autism assessment could be administered via telehealth with similar levels of usability and reliability as face-to-face assessments. However, an important limitation to note is that these participants already had a diagnosis of ASD, and thus stakes for an accurate diagnosis were not considered. Additionally, certain items on the ADOS-2 could not be administered remotely. Juárez and colleagues conducted a tele-evaluation with families of children with concerns of ASD, and $13 \%$ of participating providers did not feel comfortable making the diagnosis via telehealth and $20 \%$ of children diagnosed with ASD in-person were not diagnosed via telehealth (Juárez et al., 2018). Schutte 
and colleagues found that the ADOS-2 Module 4 (used with older adolescents and adults who exhibit fluent speech) could be viably delivered via telehealth as it relies more on conversation than the use of manipulatives to ascertain samples of reciprocal social behavior. Most participants found the platform was effective and user friendly, and allowed the diagnostician to capture patients' social communication and behavior (Schutte et al., 2015).

Results of these studies suggest a potential benefit of using telehealth to accurately diagnose ASD. However, these studies also highlight potential challenges in diagnosis via telehealth for children with more subtle presentations and less severe symptoms of ASD, where in-person assessment would be required. Additionally, some items on the ADOS-2 require manipulatives which can lead to truncating an evaluation to make it feasible (if no parent or staff is present at the originating site to facilitate). Additionally, other aspects of a complete diagnostic evaluation such as completing a physical checkup with a medical provider are also challenging via telehealth. Thus, telehealth may be used in diagnostic assessments of ASD, but standard protocols and preconceived notions about elements of an evaluation must be altered, while maintaining quality and evidence-based approaches (see chapter "Interdisciplinary Evaluation of Autism Spectrum Disorder" for more information about interdisciplinary evaluation).

\section{Telehealth and Early Intensive Intervention}

Early intensive behavioral intervention (EIBI) strategies based on the principles of Applied Behavioral Analysis (ABA) with parent psychoeducation are the most effective intervention in ASD (Makrygianni \& Reed, 2010; Reichow, 2012; Reichow, Hume, Barton, \& Boyd, 2018). Generally, the overarching goal of ABA, developed by Ivar Lovaas, is to increase behaviors that positively influence a child's learning and development, while decreasing behaviors that are interfering by changing immediate antecedents and consequences to behaviors (Smith \& Eikeseth 2010). A study of five meta-analyses of EIBI indicated that ABA is effective in improving various areas of development and functioning for children with ASD including adaptive skills (i.e., activities of daily living), IQ, and language (Reichow et al., 2018). However, the availability of therapists and programs that offer ABA vary across the country and are more limited in more rural areas (Antezana, Scarpa, Valdespino, Albright, \& Richey, 2017; Heflinger, Shaw, Higa-McMillan, Lunn, \& Brannan, 2015). Even for communities that provide more options to obtain ABA therapy, there can often be lengthy waitlists to be matched with a provider. Thus, there is greater interest in exploring the feasibility of implementing telehealth-supported behavioral interventions. Ferguson et al. (2019) conducted a systematic literature review of 28 studies, and found that while telehealth can be used for both diagnosis and treatment for ASD, telehealth failed to meet criteria for being considered a true evidence-based treatment due to methodological issues in the studies. They accordingly suggested that more research was needed to determine whether telehealth is a truly efficacious treatment 
model. Of note, Discrete Trial Training (DTT), which is a highly researched and evidence-based treatment in ASD and functional/daily living skills training, was not included in the review. See chapters "Coordinating ABA Services" and "The Early Start Denver Model (ESDM)” for more information about ABA therapies.

\section{Additional Therapies Via Telehealth}

Given the complex neurodevelopmental profile of individuals with ASD individuals and their varied strengths and areas of need, as well as co-occurring conditions, not all clients may benefit from ABA therapies. Additional modalities such as cognitivebehavioral therapy (CBT) and speech-language therapy may be more applicable or helpful to a particular child, though these therapies can also be difficult to obtain, especially for families in rural areas.

\section{CBT}

Hepburn and colleagues conducted a case study on a manualized telehealth-based CBT treatment for individuals with co-occurring ASD and anxiety and found acceptability for most participants with some limitations around technical difficulties (Internet connectivity, sound quality), which could be troubleshot in advance (Hepburn, Blakeley-Smith, Wolff, \& Reaven, 2016). However, there is very limited research examining potential telehealth CBT treatment for ASD and co-occurring mental health conditions such as depression and anxiety.

\section{Speech and Language Therapy}

Individuals with ASD often experience severe communication impairments (Simacek, Dimian, \& McComas, 2017). A systematic review of the literature about speech and language therapy via telehealth (Sutherland, Trembath, \& Roberts, 2018) concluded that families who received speech and language therapy via telehealth had equivalent outcomes to that of in-person treatment. Simacek et al. (2017) conducted a study evaluating the efficacy of providing communication intervention coaching for caregivers via telehealth. Results of their study demonstrated that all children met their communication goals and benefited from this modality of telehealth treatment). See chapter "Coordinating Speech-Language Pathology Services for Youth with Autism Spectrum Disorder" for more information about speech and language therapies. 


\section{Telepsychiatry}

Telepsychiatry generally can be done with little variation from usual in-person care due to its emphasis on verbal and nonverbal communication and clinical observations. Over the last decade, increased use of telepsychiatry has resulted in the American Academy of Child and Adolescent Psychiatry (AACAP) to issue a practice parameter (American Academy of Child and Adolescent Psychiatry (AACAP) Committee on \& Telepsychiatry and AACAP Committee on Quality Issues, 2017). Telepsychiatry can be delivered through either a traditional "direct care model", in which the psychiatrist assumes the role of medication management, or a "consultative model", in which the primary care provider (PCP) assumes the role of medication management with the psychiatrist providing guidance and consultation. A combination model "Collaborative-Care Model" involves both the PCP and psychiatrist as well as a local treatment team, including staff, case managers, and other providers (social workers, therapists) (Szeftel et al., 2011). However, there is yet no published literature on outcomes or comparative effectiveness of telepsychiatry in ASD. See chapter "Psychopharmacology of Autism Spectrum Disorder" for more information about psychopharmacology.

Overall, telehealth is emerging as a potential mode for both initial diagnosis as well as treatment for individuals with ASD and their families. Although more research is required, emerging themes of benefits and limitations have been highlighted. See Table 1 highlighting initial benefits and limitations to treatment of ASD via telehealth.

\section{Professional Training}

Training serves to increase the number of intervention professionals and ongoing professional training enables service providers to learn and keep themselves updated on evidence-based intervention techniques to implement with children and families in their communities. Vismara and colleagues conducted a study examining the efficacy of training Early Intervention providers live versus telehealth (Vismara, Young, Stahmer, Griffith, \& Rogers, 2009) to learn direct treatment and parent coaching. They found no significant differences in therapists' skill level and reported satisfaction between those who participated in the live training versus telehealth. Similarly, Ruble and colleagues conducted a randomized controlled study of ASD looking at specific coaching to teachers in person and via web-based modality. Results showed that students did equally well in both groups (Ruble, McGrew, Toland, Dalrymple, \& Jung, 2013). 
Table 1 Benefits and limitations of telehealth in ASD

\begin{tabular}{|c|c|}
\hline Benefits & Limitations \\
\hline $\begin{array}{l}\text { Can provide diagnosis and treatment options } \\
\text { to a wider range of families who live in rural } \\
\text { or underserved populations }\end{array}$ & Potential for technical difficulties \\
\hline $\begin{array}{l}\text { Can be a more cost-effective way to provide } \\
\text { educational and therapeutic intervention } \\
\text { compared to in-home therapies }\end{array}$ & Potential risk to maintaining confidentiality \\
\hline $\begin{array}{l}\text { May be a shorter wait time to be seen by a } \\
\text { provider who is specialized in ASD treatment }\end{array}$ & $\begin{array}{l}\text { Potential difficulty scheduling emergency } \\
\text { sessions }\end{array}$ \\
\hline $\begin{array}{l}\text { Has shown to be effective in training } \\
\text { therapists, teachers, and parents specialized in } \\
\text { ASD therapeutic techniques which can be } \\
\text { implemented at home and in the community }\end{array}$ & $\begin{array}{l}\text { Longer wait time for prescriptions when } \\
\text { electronic prescribing is not possible }\end{array}$ \\
\hline $\begin{array}{l}\text { Is generally received well from those who } \\
\text { receive training and treatment }\end{array}$ & $\begin{array}{l}\text { Difficulty providing supplementary written } \\
\text { materials to families }\end{array}$ \\
\hline $\begin{array}{l}\text { Decreases the time children and families wait } \\
\text { to access care which can lead to earlier } \\
\text { initiation of interventions and more consistent } \\
\text { therapy over the course of development }\end{array}$ & $\begin{array}{l}\text { May make establishing rapport and trust with } \\
\text { families more difficult when engaging through } \\
\text { video rather than in person }\end{array}$ \\
\hline May decrease the need to miss school or work & $\begin{array}{l}\text { Wide variation in reimbursement for services } \\
\text { provided via telehealth in the United States } \\
\text { which may limit providers ability to provide } \\
\text { care }\end{array}$ \\
\hline $\begin{array}{l}\text { Limits transportation requirement for families } \\
\text { without transportation or for individuals with } \\
\text { ASD who have difficulty with transition, } \\
\text { being in a car, or clinic/hospital setting }\end{array}$ & $\begin{array}{l}\text { More difficult to detect with more subtle } \\
\text { presentations of ASD }\end{array}$ \\
\hline $\begin{array}{l}\text { Potential for multiple specialty providers to } \\
\text { work with an individual which may provide a } \\
\text { greater level of interprofessional care and } \\
\text { collaboration. }\end{array}$ & $\begin{array}{l}\text { Insurance policies often require one in person } \\
\text { visit before establishing telehealth care }\end{array}$ \\
\hline
\end{tabular}

\section{Parent Training}

Parents and caregivers know their child best, and their involvement in interventions is important. They help professionals understand a child's unique areas of strength and challenges and can ensure consistent implementation of therapeutic techniques in the home and community settings. Researchers have investigated the use of telehealth to provide therapeutic intervention for parents of children with ASD. Lindgren and colleagues compared the effects of assessing and analyzing functions of challenging behavior and implementation of functional communication training in clinic-based telehealth, in-home therapy, and home-based telehealth to help parents manage difficult behaviors in children with ASD (Lindgren et al., 2016). They concluded that all three modalities led to a significant reduction of problem behavior ( $>$ $90 \%$ ), and parent-rated acceptability was high for all groups. Interestingly, they also 
concluded that home-based telehealth delivered through videoconferencing was the most cost-effective way to provide treatment to families.

Research findings suggest that not only is telehealth a potential method to reach more families, but it is more cost-effective as well. Many studies (Heitzman-Powell, Buzhardt, Rusinko, \& Miller, 2014; Ingersoll, Wainer, Berger, Pickard, \& Bonter, 2016) have evaluated the efficacy of parent training (for families in rural areas with a wide variety of educational backgrounds) via telehealth and found it to be feasible and effective, though larger sample sizes would be needed to make a more definitive conclusion. For example, Heitzman-Powell et al. (2014) note that families from rural areas who completed their training spent less time and money traveling with the telehealth training model compared to in-person visits.

\section{Guidance for Clinicians}

For interdisciplinary clinicians interested in leveraging telehealth to serve families and children with ASD, there are several areas to be aware of and to address if telehealth for ASD is to become acceptable and sustainable in their communities.

\section{Getting Started}

Clinicians should view telehealth as a modality for delivering care instead of a separate form of care. The first step is for the clinician to recognize the geographic draw of patients/families and the burden of travel they endure to access traditional in-person services. Data from the EHR can be used for planning prospective community sites to deliver telehealth (Soares, Dewalle, \& Marsh, 2017). Engaging community partners (local practices, outpatient centers) can help identify the originating sites, and community partnerships showcase collaborations with specialists in ASD and provide a closer-to-home option for families. Analyzing gaps in service is an important step in developing a business proposition for expanding telehealth, whether through the capture of new geographic and demographic constituencies or serving as a marketing opportunity to demonstrate family-centered community partnerships and thus increase market share. By reducing geographic barriers (an important contributor to no-show rates), organizations can capture revenue otherwise lost.

Clinicians interested in leveraging telehealth can engage in "pilot projects" with a limited subset of the population: geographically, specific diagnoses, specific visit types (e.g., return office visits only). It is important to understand what measures are used by systems, particularly around patient satisfaction, such as Press Ganey's recently developed two Telemedicine for Medical Practice Surveys (Press Ganey, n.d.), though there are no studies comparing satisfaction between telehealth and in-person visits. 


\section{Process and Workflow}

Operationally, for systems to embrace telehealth, support from senior leadership is key to committing resources (equipment, personnel) to launch a program, and balancing the impact of a new program on existing "in person" delivery with regards to space, time, and resource allocation. There can also be concerns from staff around time/effort spent in training on telehealth, including division of roles/responsibilities between usual care and telehealth care, particularly in systems without designated roles for telehealth. Similar workflow concerns can arise with delivering telehealth providers as many protocols veer from their "usual practice" of patients in clinic rooms, such as the use of a designated room, workflow (including connectivity) that also is different from in-person care, and concerns around time spent/lost in setting up and completing the encounter. This can be counterbalanced by improved access and completed visits (through possibly reducing no-show rates).

Systems must work with clinicians to identify "champions" at every level (clinicians, staff) and empower them to identify areas of improvement through telehealth in their practice and that of their colleagues (Ellimoottil, An, Moyer, Sossong, \& Hollander, 2018). Champions can energize colleagues by sharing results of pilot initiatives to show how telehealth aligns with the system's mission and strengthens existing initiatives (including improving access and the overall patient experience) (Ellimoottil et al., 2018).

\section{Professional Education}

Increasing the workforce in telehealth-clinicians and facilitators/coordinators at both the originating and distal sites-is an important step to address increasing demand to serve families challenged with ASD. There is an increasing number of training programs, educational modules, and hands-on practicum to teach staff to facilitate, evaluate, and advocate for telehealth in their organizations (Papanagnou, Sicks, \& Hollander, 2015). Continuing education programming and rotational experiences with trainees should underscore professional practice standards, user factors including privacy, and fluency with telehealth technologies (modalities, security, operations) (Committee on Pediatric Workforce, 2015).

Clinicians and leaders can enhance their own knowledge and skills around telehealth through training and education. Networking and learning can be achieved at numerous national conferences such as the American Telemedicine Association (ATA) and Healthcare Information and Management Systems Society (HIMSS) annual meetings. There are many ATA resources such as practice guidelines and best practices on pediatrics (McSwain et al., 2017) and mental health (Myers et al., 2017). For clinicians desiring a higher level of skill, there are certificate courses in telehealth and even clinical informatics fellowships that provide training on a broad array of biomedical data, computational systems, and clinical process improvement. 


\section{Client Factors}

Families and patients are generally satisfied with telehealth (Weinstein et al., 2014), in part due to improved access to care and reduced burden of travel. Millennials and Generation Xers are more likely than older patients to consider telehealth (Fronstin \& Dretzka, 2017), particularly for follow-up visits (Donelan et al., 2019). It is important to maintain a perspective of family-centered care (Kuo et al., 2012), which includes delivering care in their communities to reduce the burden of job-related absence and cost of travel (Soares et al., 2013). Families appear to be ready to engage in telehealth; almost $80 \%$ of mothers want to learn more about telehealth for acute, non-emergency medical issues and $65 \%$ view it as convenient and not disruptive to school or daily routines (EmpowHER®, n.d.). Family and patient education using signage, patient detailing materials, and "show and tell" open houses can also help to increase awareness and demystify notions around telehealth.

\section{Licensure and Reimbursement}

Recent efforts to ease licensure burdens on providers are evident, notably the Interstate Medical Licensure Compact which provides an expedited pathway to licensure across multiple states. By the end of 2019, 29 states, District of Columbia and Guam are part of the compact (IMLC Commission, n.d.). Similarly, 12 states have signed on to the Psychology Interjurisdictional Compact (PSYPACT), developed by the Association of State and Provincial Psychology Boards (ASPPB), which will allow psychologists to avail expedited credentialing in the near future to use telehealth technology (The Association of State and Provincial Psychology Boards, n.d.). Under Medicare legislation, speech-language pathologists are not currently able to provide telehealth services (American Speech Language Hearing Association, n.d.).Reimbursement for ABA delivered via telehealth also varies by state, and, even if permitted, coverage may be limited (Frank, n.d.).

Most states do not have restrictions on Medicaid reimbursements when telehealth is used in rural areas; but Medicare regulations still have restrictions to the "originating site" being located in certain types of geographic areas (rural health professional shortage area or a county outside of a Metropolitan Statistical Area (Centers for Medicare \& Medicaid Services, 2018). By the end of 2019, only 14 states (Center for Connected Health Policy, 2019) explicitly allow telehealth delivery in the home (but only under certain circumstances). While there is no sweeping requirement to have an in-person encounter prior to delivering telehealth, in some states, advanced practitioners, psychologists, and counselors must still see patients in person before providing telehealth. Ease in provider credentialing policies has also eased the burden on the prospective telehealth provider (Centers for Medicare \& Medicaid Services, 2011). 


\section{Technology Factors}

Technology options abound today for telehealth; with the basic needs for synchronous telehealth being a monitor/display, camera, speakers, microphone, and a connection portal (either hardware or software). Equipment varies in terms of size, available options, mobility (fixed versus mobile), with varying cost of actual equipment, maintenance, and upgrades. A prospective program has to identify equipment requirements that match with the specific program's need and operability within their institution's larger Information Technology (IT) infrastructure. Seeking consultation from institutional IT specialists as well as other content experts (like regional Telehealth Resource Centers) helps, but should always include the key stakeholders actually involved in encounters (staff, clinicians, and families). A videoconferencing platform must be compliant with the Health Insurance Portability and Accountability Act (HIPAA; Codified at 42 U.S.C. §1320d et seq. and §300gg; and 29 U.S.C. §1181 et seq., 1996), and security risks can be mitigated with end-to-end encryption and by using protections against malware and other security breaches.

\section{Future Directions}

With increasing consumer demand for efficient, accessible options for care delivery, and technology innovation yielding devices capable of such delivery, there will be a need to offer telehealth interventions and coordination for families and children with ASD to a greater extent than currently available. With no end in sight to health professional shortages and a continuing disparity in access for rural and underserved urban populations, an important family-centered direction is to permit telehealth delivery in the home. This allows for better access, particularly for families with transportation and childcare challenges, and observing the child in his/her naturalistic environment allows for more accurate data collection and more family-centered recommendations. Legislation underway in the US Congress includes the Mental Health Telemedicine Expansion Act (H.R. 6781), designed to increase access to mental health services through telehealth by allowing the patient's home to be an originating site (DelBene \& Reed, 2018).

Access is the prime driver for telehealth in ASD, and clinicians and family advocates should share this perspective with policy makers, payers, and other individuals who can facilitate the sustainability of telehealth. An important effort is to continue to reduce licensure and regulatory barriers, and optimize reimbursement. Clinicians should become familiar with recent reimbursement codes around telehealth that have implications in ASD care coordination. (Center for Connected Health Policy, n.d.). Advocacy for payment is important since levels of private payer reimbursement continue to be low (Medicare Payment Advisory Commission [MedPAC], 2018).

Developing and extending the research-base for telehealth is an important endeavor for multiple reasons: it provides information for policy makers to base their 
decisions around reimbursement and regulations (Agboola, Hale, Masters, Kvedar, \& Jethwani, 2014) and allows sharing of evidence-based strategies among the clinical and research community. Until recently, telehealth research had been heterogeneous with studies of mixed quality and varied outcomes, making it difficult to estimate pooled effects (Ekeland, Bowes, \& Flottorp, 2012). In addition to the usual randomized, controlled trials (RCTs), new collaborative research methodologies and novel analytic techniques emphasizing patient outcomes, large-scale feasibility, and cost-effectiveness will be needed (Tuckson, Edmunds, \& Hodgkins, 2017). There is sufficient evidence to support effectiveness around communication and counseling for patients with chronic conditions, and psychotherapy as part of behavioral health (Totten et al., 2016). Building on this research-base will be important to select outcomes with two viewpoints: (a) to replicate and/or compare rates and effect sizes of developmental and behavioral outcomes to traditional intervention studies (Fein et al., 2013); and (b) to identify meaningful outcomes (including their measurement) while maintaining an inclusive spectrum approach to ASD (Georgiades \& Kasari, 2018).

\section{Epilogue: The COVID-19 Effect}

In early 2020, Coronavirus disease 2019 (COVID-19) erupted around the globe, and by mid-March 2020 the US declared a pandemic emergency. As a result, swift changes in regulations in favor of telehealth occurred; including reduced barriers to access (Centers for Medicare \& Medicaid Services, 2020) such as waiving co-pays associated with telehealth visits, permitting delivery of care to the patient's home, permitting both new and established patients to receive telehealth, among others. At the same time, US Department of Health and Human Services expanded the use of public facing technologies which may not fully comply with the requirements of the HIPAA Rules, as long as conducted with the good faith provision of telehealth during the crisis (Department of Health \& Human Services, 2020). This meant a lot of previously seldom used platforms for telehealth such as Apple FaceTime, Facebook Messenger, Google Hangouts, Zoom, or Skype could be used; however providers are still responsible to notify patients about potential privacy risks with these applications, and should use available encryption and privacy modes as much as possible.

COVID-19 social distancing restrictions are creating even longer wait times for families to receive an in-person evaluation as well as follow up care and intervention. Thus, clinicians and researchers are developing and beginning to implement new assessment tools as well as modify existing instruments in order to provide telehealth assessment and diagnosis of ASD. The Vanderbilt University team have developed assessment tools that can be administered via telehealth. A diagnostic measure, Telemedicine-based Autism Spectrum Disorder Assessment in Toddlers (TELE-ASD-PEDS), can be administered remotely either in a clinic or home setting by a qualified provider (with expertise in diagnosing ASD) observing via video 
(Corona et al., 2020). While there is ongoing data collection and validation of the tools for use via telehealth, the group has shared the training and tools with clinicians for use during COVID-19. Additionally, many major psychometric testing companies are moving towards making available digital test administration and scoring for remote options.

While welcome, this has left clinicians scrambling to balance patient access vs. becoming familiar with new processes/technologies/delivery of standard instruments at a time when many are secluded at home, while some are furloughed or deployed to other critical areas of the healthcare or service delivery system. Although not published, certain ABA companies in the US are offering virtual therapy and intervention to families as well, and professional organizations from psychology to speech therapy are putting out guidance on telepractice delivery.

Although the duration of social distancing practices are unknown at this time and will depend on local public health guidance, the COVID-19 crisis has certainly advanced the use of telehealth. There will likely be an increase in telehealth moving forward even after restrictions have been lifted, and with more research and validation of novel tools, clinicians will hopefully be able to provide access to assessment and treatment to underserved populations.

\section{References}

Agboola, S., Hale, T. M., Masters, C., Kvedar, J., \& Jethwani, K. (2014). "Real-world” practical evaluation strategies: A review of telehealth evaluation. JMIR Research Protocols, 3, e75.

American Academy of Child and Adolescent Psychiatry (AACAP) Committee on, \& Telepsychiatry and AACAP Committee on Quality Issues. (2017). Clinical update: telepsychiatry with children and adolescents. Journal of the American Academy of Child and Adolescent Psychiatry, 56, 875-893.

American Speech Language Hearing Association. (n.d.). Reimbursement of telepractice services.

American Well. (2019). Telehealth Index 2019 Physician Survey.

Antezana, L., Scarpa, A., Valdespino, A., Albright, J., \& Richey, J. A. (2017, April). Rural trends in diagnosis and services for autism spectrum disorder. Frontiers in Psychology, 8.

Bridgemohan, C., Bauer, N. S., Nielsen, B. A., DeBattista, A., Ruch-Ross, H. S., Paul, L. B., et al. (2018). A workforce survey on developmental-behavioral pediatrics. Pediatrics, 141, e20172164.

Center for Connected Health Policy. (n.d.). Retrieved September 15, 2019, from https://mailchi. $\mathrm{mp} / \mathrm{cchpca}$ /big-changes-in-2019-for-medicare-telehealth-policy.

Center for Connected Health Policy. (2019). State telehealth laws and medicaid program policies.

Centers for Medicare \& Medicaid Services. (2011). Medicare and medicaid programs: Changes affecting hospital and critical access hospital conditions of participation: telemedicine credentialing and privileging.

Centers for Medicare \& Medicaid Services. (2018). Information on medicare telehealth.

Centers for Medicare \& Medicaid Services. (2020). Physicians and other clinicians: CMS flexibilities to fight COVID-19.

Chiri, G., \& Warfield, M. E. (2012). Unmet need and problems accessing core health care services for children with autism spectrum disorder. Maternal and Child Health Journal, 16, 1081-1091.

Chlebowski, C., Robins, D. L., Barton, M. L., \& Fein, D. (2013). Large-scale use of the modified checklist for autism in low-risk toddlers Pediatrics, 131. 
Committee on Pediatric Workforce. (2015). The use of telemedicine to address access and physician workforce shortages. Pediatrics, 136, 202-209.

Corona, L., Hine, J., Nicholson, A., Stone, C., Swanson, A., Wade, J., Wagner, L., Weitlauf, A., \& Warren, Z. (2020). TELE-ASD-PEDS: A telemedicine-based ASD evaluation tool for toddlers and young children. Vanderbilt University Medical Center. https://vkc.vumc.org/vkc/triad/teleasd-peds.

Dawson, G., \& Bernier, R. (2013). A quarter century of progress on the early detection and treatment of autism spectrum disorder. Development and Psychopathology, 25, 1455-1472.

DelBene, S., \& Reed, T. (2018). Mental health telemedicine expansion act (HR 6781).

Donelan, K., Barreto, E. A., Sossong, S., Michael, C., Estrada, J. J., Cohen, A. B., ... Schwamm, L. H. (2019). Patient and clinician experiences with telehealth for patient follow-up care. The American Journal of Managed Care, 25, 40-44.

Ekeland, A. G., Bowes, A., \& Flottorp, S. (2012). Methodologies for assessing telemedicine: A systematic review of reviews. International Journal of Medical Informatics, 81, 1-11.

Ellimoottil, C., An, L., Moyer, M., Sossong, S., \& Hollander, J. E. (2018). Challenges and opportunities faced by large health systems implementing telehealth. Health Affairs, 37, $1955-1959$.

EmpowHER®. (n.d.). Moms and health technology survey. Retrieved from http://www. empowher.com/healthy-technology/content/infographic-are-you-tech-savvy-mom-see-whatour-community-said.

Fair Health Inc. (2018). FH Healthcare Indicators and FH medical price index: A new view of place of service trends and medical pricing.

Federal Communications Commission. (2018). Broadband deployment report 2018.

Fein, D., Barton, M., Eigsti, I.-M., Kelley, E., Naigles, L., Schultz, R. T., ... Tyson, K. (2013). Optimal outcome in individuals with a history of autism. Journal of Child Psychology and Psychiatry, 54, 195-205.

Filipek, P. A., Accardo, P. J., Ashwal, S., Baranek, G. T., Cook, E. H., Dawson, G., ... Volkmar, F. R. (2000). Practice parameter: screening and diagnosis of autism: report of the Quality Standards Subcommittee of the American Academy of Neurology and the Child Neurology Society. Neurology, 55, 468-479.

Frank, H. (n.d.). Telehealth: ABA's new frontier. Retrieved from BSci21.org, https://bsci21.org/ telehealth-abas-new-frontier/.

Fronstin, P., \& Dretzka, E. (2017). Consumer engagement in health care among millennials, baby boomers, and generation $x$ : Findings from the 2017 consumer engagement in health care survey.

Georgiades, S., \& Kasari, C. (2018). Reframing optimal outcomes in autism. JAMA Pediatrics, 172, 716.

Gordon-Lipkin, E., Foster, J., \& Peacock, G. (2016, October 1). Whittling down the wait time: Exploring models to minimize the delay from initial concern to diagnosis and treatment of autism spectrum disorder. Pediatric Clinics of North America, 63, 851-859.

Health Insurance Portability and Accountability Act. (1996). Codified at 42 U.S.C. \$1320d et seq. and \$300gg; and 29 U.S.C. \$1181 et seq.

Heflinger, C. A., Shaw, V., Higa-McMillan, C., Lunn, L., \& Brannan, A. M. (2015). Patterns of child mental health service delivery in a public system: Rural children and the role of rural residence. Journal of Behavioral Health Services and Research, 42, 292-309.

Heitzman-Powell, L. S., Buzhardt, J., Rusinko, L. C., \& Miller, T. M. (2014). Formative evaluation of an ABA outreach training program for parents of children with autism in remote areas. Focus on Autism and Other Developmental Disabilities, 29, 23-38.

Hepburn, S. L., Blakeley-Smith, A., Wolff, B., \& Reaven, J. A. (2016). Telehealth delivery of cognitive-behavioral intervention to youth with autism spectrum disorder and anxiety: A pilot study. Autism, 20, 207-218.

Huerta, M., \& Lord, C. (2012). Diagnostic evaluation of autism spectrum disorders. Pediatric Clinics of North America, 59, 103-111. 
IMLC Commission. (n.d.). Interstate medical licensure compact. Retrieved May 31, 2019, from https://imlcc.org/.

Ingersoll, B., Wainer, A. L., Berger, N. I., Pickard, K. E., \& Bonter, N. (2016). Comparison of a self-directed and therapist-assisted telehealth parent-mediated intervention for children with ASD: A pilot RCT. Journal of Autism and Developmental Disorders, 46, 2275-2284.

Johnson, C. P., \& Myers, S. M. (2007). Identification and evaluation of children with autism spectrum disorders: Guidance for the clinician in rendering pediatric care. Pediatrics, 120, 1183-1215.

Juárez, A. P., Weitlauf, A. S., Nicholson, A., Pasternak, A., Broderick, N., Hine, J., ... Warren, Z. (2018). Early Identification of ASD Through telemedicine: Potential value for underserved populations. Journal of Autism and Developmental Disorders, 48, 2601-2610.

KLAS. (2017). Telehealth virtual care platforms 2017: An early look at the state oftelehealth.

KLAS. (2018). Telehealth virtual care platforms: Which telehealth vendors have the scalability customers need?

Kuo, D. Z., Houtrow, A. J., Arango, P., Kuhlthau, K. A., Simmons, J. M., \& Neff, J. M. (2012). Family-centered care: Current applications and future directions in pediatric health care. Maternal and Child Health Journal, 16, 297-305.

Lindgren, S., Wacker, D., Suess, A., Schieltz, K., Pelzel, K., Kopelman, T., ... Waldron, D. (2016). Telehealth and autism: Treating challenging behavior at lower cost. Pediatrics, 137, S167-S175.

Makrygianni, M. K., \& Reed, P. (2010). October). A meta-analytic review of the effectiveness of behavioural early intervention programs for children with autistic spectrum disorders. Research in Autism Spectrum Disorders, 4, 577-593.

Maenner, M. J., Shaw, K. A., Baio, J., Washington, A., Patrick, M., DiRienzo. M., et al. (2020). Prevalence of autism spectrum disorder among children aged 8 years. Autism and Developmental Disabilities Monitoring, 69, 1-12. https://www.cdc.gov/mmwr/volumes/69/ss/ss6904a1.htm.

McSwain, S. D., Bernard, J., Burke, B. L., Cole, S. L., Dharmar, M., Hall-Barrow, J., ... Yeager, B. (2017). American Telemedicine Association operating procedures for pediatric telehealth. Telemedicine and E-Health, 23, 699-706.

Medicare Payment Advisory Commission (MedPAC). (2018). Mandated report: Telehealth services and the Medicare program. Retrieved from http://www.medpac.gov/docs/default-source/reports/ mar18_medpac_ch16_sec.pdf?sfvrsn=0.

Myers, K., Nelson, E.-L., Rabinowitz, T., Hilty, D., Baker, D., Barnwell, S. S., .. Bernard, J. (2017). American Telemedicine Association practice guidelines for telemental health with children and adolescents. Telemedicine and E-Health, 23, 779-804.

Ning, M., Daniels, J., Schwartz, J., Dunlap, K., Washington, P., Kalantarian, H., ... Wall, D. P. (2019). Identification and quantification of gaps in access to autism resources in the United States: An infodemiological study. Journal of Medical Internet Research, 21, e13094.

Office for the Advancement of Telehealth. (n.d.). Retrieved May 28, 2019, from https://www.hrsa. gov/rural-health/telehealth/index.html.

Pakyurek, M., Yellowlees, P., \& Hilty, D. (2010). The child and adolescent telepsychiatry consultation: Can it be a more effective clinical process for certain patients than conventional practice? Telemedicine and E-Health, 16, 289-292.

Papanagnou, D., Sicks, S., \& Hollander, J. E. (2015). Training the next generation of care providers: Focus on telehealth. Healthcare Transformation, 1, 52-63.

Pew Research Center. (n.d.). Mobile Fact Sheet. Retrieved June 1, 2019, from 2018 website: https:// www.pewinternet.org/fact-sheet/mobile/.

Pierce, K., Carter, C., Weinfeld, M., Desmond, J., Hazin, R., Bjork, R., \& Gallagher, N. (2011). Detecting, studying, and treating autism early: The one-year well-baby check-up approach. Journal of Pediatrics, 159.

Press Ganey. (n.d.). Telemedicine for medical practice surveys. Retrieved from https://www. pressganey.com/docs/default-source/default-document-library/telemedicine-for-medicalpractice_faqs_040918.pdf?sfvrsn=0. 
Reese, R. M., Jamison, R., Wendland, M., Fleming, K., Braun, M. J., Schuttler, J. O., et al. (2013). Evaluating interactive videoconferencing for assessing symptoms of Autism. Telemedicine and E-Health, 19, 671-677.

Reichow, B. (2012). Overview of meta-analyses on early intensive behavioral intervention for young children with autism spectrum disorders. Journal of Autism and Developmental Disorders, 42, 512-520.

Reichow, B., Hume, K., Barton, E. E., \& Boyd, B. A. (2018, May 9). Early intensive behavioral intervention (EIBI) for young children with autism spectrum disorders (ASD). In: Cochrane database of systematic reviews (Vol. 2018). John Wiley and Sons Ltd.

Ruble, L. A., McGrew, J. H., Toland, M. D., Dalrymple, N. J., \& Jung, L. A. (2013). A randomized controlled trial of COMPASS web-based and face-to-face teacher coaching in autism. Journal of Consulting and Clinical Psychology, 81, 566-572.

Schutte, J. L., McCue, M. P., Parmanto, B., McGonigle, J., Handen, B., Lewis, A., ... Saptono, A. (2015). Usability and reliability of a remotely administered adult autism assessment, the autism diagnostic observation schedule (ADOS) module 4. Telemedicine and E-Health, 21, 176-184.

Shattuck, P. T., Durkin, M., Maenner, M., Newschaffer, C., Mandell, D. S., Wiggins, L., ... Cuniff, C. (2009). Timing of identification among children with an autism spectrum disorder: Findings from a population-based surveillance study. Journal of the American Academy of Child and Adolescent Psychiatry, 48, 474-483.

Siklos, S., \& Kerns, K. A. (2007). Assessing the diagnostic experiences of a small sample of parents of children with autism spectrum disorders. Research in Developmental Disabilities, 28, 9-22.

Simacek, J., Dimian, A. F., \& McComas, J. J. (2017). Communication intervention for young children with severe neurodevelopmental disabilities via telehealth. Journal of Autism and Developmental Disorders, 47, 744-767.

Soares, N., Johnson, A. O., \& Patidar, N. (2013). Geomapping telehealth access to developmentalbehavioral pediatrics. Telemedicine and E-Health, 19, 585-590.

Soares, Neelkamal, Dewalle, J., \& Marsh, B. (2017). Utilizing patient geographic information system data to plan telemedicine service locations. Journal of the American Medical Informatics Association, 24, 891-896.

Soares, N. S., \& Langkamp, D. (2012). Telehealth in developmental-behavioral pediatrics. Journal of Developmental and Behavioral Pediatrics, 33, 656-665.

Stahmer, A. C., \& Mandell, D. S. (2007). State infant/toddler program policies for eligibility and services provision for young children with autism. Administration and Policy in Mental Health and Mental Health Services Research, 34, 29-37.

Sutherland, R., Trembath, D., \& Roberts, J. (2018). Telehealth and autism: A systematic search and review of the literature. International Journal of Speech-Language Pathology, 20, 324-336.

Szeftel, R., Mandelbaum, S., Sulman-Smith, H., Naqvi, S., Lawrence, L., Szeftel, Z., ... Gross, L. (2011). Telepsychiatry for children with developmental disabilities: Applications for patient care and medical education. Child and Adolescent Psychiatric Clinics of North America, 20, 95-111.

The Association of State and Provincial Psychology Boards. (n.d.). PSYPACT Legislative Updates. Retrieved from https://www.asppb.net/mpage/legislative.

Totten, A., Womack, D., Eden, K., McDonagh, M., Griffin, J., Grusin, S., \& Hersh, W. (2016). Telehealth: mapping the evidence for patient outcomes from systematic reviews. Technical Brief No. 26. Retrieved from www.effectivehealthcare.ahrq.gov/reports/final.cfm.

Tuckson, R. V., Edmunds, M., \& Hodgkins, M. L. (2017). Telehealth. New England Journal of Medicine, 377, 1585-1592.

U.S. Department of Health \& Human Services. (2020). Notification of enforcement discretion for telehealth remote communications during the COVID-19 Nationwide public health emergency.

Utidjian, L., \& Abramson, E. (2016). Pediatric telehealth: opportunities and challenges. Pediatric Clinics of North America, 63, 367-378.

Vismara, L. A., Young, G. S., Stahmer, A. C., Griffith, E. M. M., \& Rogers, S. J. (2009). Dissemination of evidence-based practice: can we train therapists from a distance? Journal of Autism and Developmental Disorders, 39, 1636-1651. 
Wagner, S., Granpeesheh, D., Wetherby, A., Natowicz, M. R., Choueiri, R., Pierce, K., ... Robins, D. (2015). Early intervention for children with autism spectrum disorder under 3 years of age: recommendations for practice and research. Pediatrics, 136, S60-S81.

Warren, Z., McPheeters, M. L., Sathe, N., Foss-Feig, J. H., Glasser, A., \& Veenstra-VanderWeele, J. (2011). A systematic review of early intensive intervention for autism spectrum disorders. Pediatrics, 127, e1303-e1311.

Weinstein, R. S., Lopez, A. M., Joseph, B. A., Erps, K. A., Holcomb, M., Barker, G. P., et al. (2014). Telemedicine, telehealth, and mobile health applications that work: opportunities and barriers. The American Journal of Medicine, 127, 183-187.

Zuckerman, K. E., Lindly, O. J., \& Sinche, B. K. (2015). Parental concerns, provider response, and timeliness of autism spectrum disorder diagnosis. Journal of Pediatrics, 166, 1431-1439.e1.

Zwaigenbaum, L., Bauman, M. L., Choueiri, R., Kasari, C., Carter, A., Granpeesheh, D., ... Natowicz, M. R. (2015). Early intervention for children with autism spectrum disorder under 3 years of age: recommendations for practice and research. Pediatrics, 136, S60-S81. 